\title{
Dietary intake and food sources of choline in European populations
}

\author{
Francy B. C. Vennemann ${ }^{1}$, Sofia Ioannidou ${ }^{1 *}$, Liisa M. Valsta ${ }^{1}$, Céline Dumas ${ }^{2}$, Marga C. Ocké ${ }^{3}$, \\ Gert B. M. Mensink ${ }^{4}$, Oliver Lindtner ${ }^{5}$, Suvi M. Virtanen ${ }^{6}$, Christina Tlustos ${ }^{7}$, Laura D'Addezio ${ }^{8}$, \\ Irene Mattison ${ }^{9}$, Carine Dubuisson ${ }^{10}$, Inese Siksna ${ }^{11}$ and Fanny Héraud ${ }^{1}$ \\ ${ }^{1}$ Evidence Management Unit, European Food Safety Authority (EFSA), 43126 Parma, Italy \\ ${ }^{2}$ Nutrition Unit, European Food Safety Authority (EFSA), 43126 Parma, Italy \\ ${ }^{3}$ National Institute for Public Health and the Environment (RIVM), 3721 MA Bilthoven, The Netherlands \\ ${ }^{4}$ Department of Epidemiology and Health Monitoring, Robert Koch Institute, D-13302 Berlin, Germany \\ ${ }^{5}$ Exposure Assessment and Exposure Standardisation Unit, Federal Institute for Risk Assessment (BfR), D-10589 Berlin, Germany \\ ${ }^{6}$ Nutrition Unit, Institute for Health and Welfare (THL), FI-O0271 Helsinki, Finland \\ ${ }^{7}$ Food Safety Authority of Ireland (FSAI), DO1 W2H4 Dublin, Republic of Ireland \\ ${ }^{8}$ Research Center on Food and Nutrition (CRA-NUT), O0184 Rome, Italy \\ ${ }^{9}$ Risk Benefit Assessment Division, National Food Agency, 75126 Uppsala, Sweden \\ ${ }^{10}$ Dietary Survey Unit - Nutritional Epidemiology, French Agency for Food, Environmental and Occupational Health Safety \\ (ANSES), 94701 Maisons-Alfort, France \\ ${ }^{11}$ Department of Risk Assessment and Epidemiology, Institute of Food Safety, Animal Health and Environment (BIOR), \\ LV-1076 Riga, Latvia
}

(Submitted 27 October 2014 - Final revision received 18 July 2015 - Accepted 27 August 2015 - First published online 1 October 2015)

\section{Abstract}

Choline is an important nutrient for humans. Choline intake of the European population was assessed considering the European Food Safety Authority European Comprehensive Food Consumption Database and the United States Department of Agriculture Nutrient Database. Average choline intake ranges were $151-210 \mathrm{mg} / \mathrm{d}$ among toddlers ( 1 to $\leq 3$ years old), $177-304 \mathrm{mg} / \mathrm{d}$ among other children ( 3 to $\leq 10$ years old), $244-373 \mathrm{mg} / \mathrm{d}$ among adolescents (10 to $\leq 18$ years old), $291-468 \mathrm{mg} / \mathrm{d}$ among adults (18 to $\leq 65$ years old), $284-450 \mathrm{mg} / \mathrm{d}$ among elderly people ( 65 to $\leq 75$ years old) and $269-444 \mathrm{mg} / \mathrm{d}$ among very elderly people ( $\geq 75$ years old). The intakes were higher among males compared with females, mainly due to larger quantities of food consumed per day. In most of the population groups considered, the average choline intake was below the adequate intake (AI) set by the Institute of Medicine in the USA. The main food groups contributing to choline intake were meat, milk, grain, egg and their derived products, composite dishes and fish. The main limitations of this study are related to the absence of choline composition data of foods consumed by the European population and the subsequent assumption made to assess their intake levels. Given the definition of AI, no conclusion on the adequacy of choline intake can be drawn for most European population groups. Such results improve the knowledge on choline intake in Europe that could be further refined by the collection of choline composition data for foods as consumed in Europe.

\section{Key words: Choline: Nutrient intake assessment: Food composition: Food contributors: Europe}

Choline has been identified as an important nutrient for humans. Choline is predominantly obtained from the diet, but it can also be synthesised de novo ${ }^{(1)}$. In the body, choline is important for the maintenance of structural integrity of cell membranes, methyl metabolism, cholinergic neurotransmission, transmembrane signalling and lipid and cholesterol transport and metabolism ${ }^{(2)}$. Deficiency of choline has been associated with fatty liver ${ }^{(3)}$, liver damage ${ }^{(1)}$ and muscle damage ${ }^{(4)}$. As data were insufficient to set an estimated average requirement and an RDA for choline, the Institute of Medicine (IOM) in the USA

Disclaimer: The present article is published under the sole responsibility of the authors and may not be considered as a European Food Safety Authority (EFSA) scientific output. The positions and opinions presented in this article are those of the authors alone and are not intended to represent the views or scientific works of their institutes and of EFSA. To know about the views or scientific outputs of EFSA, please consult its website under http://www.efsa.europa.eu.

Abbreviations: AI, adequate intake; EFSA, European Food Safety Authority; IOM, Institute of Medicine; UL, upper intake level; USDA, United States Department of Agriculture.

* Corresponding author: S. Ioannidou, fax +39 521036 543, email sofia.ioannidou@efsa.europa.eu 
set in 1998 a number of adequate intake (AI) values depending on age and sex: $200 \mathrm{mg} / \mathrm{d}$ for children aged 1-3 years, $250 \mathrm{mg} / \mathrm{d}$ (4-8 years) and $375 \mathrm{mg} / \mathrm{d}$ (9-13 years) for children, $400 \mathrm{mg} / \mathrm{d}$ (girls) and $550 \mathrm{mg} / \mathrm{d}$ (boys) for adolescents aged 14-18 years, $425 \mathrm{mg} / \mathrm{d}$ (women) and $550 \mathrm{mg} / \mathrm{d}$ (men) for adults older than 19 years, $450 \mathrm{mg} / \mathrm{d}$ for pregnant women or adolescents and $550 \mathrm{mg} / \mathrm{d}$ for lactating women or adolescents ${ }^{(5)}$. The values for adults focused on the prevention of liver damage, based on a single study on males ${ }^{(1)}$. The values for children were derived from the AI for adults through a mathematical approach (allometric scaling) ${ }^{(1,5)}$. A tolerable upper intake level (UL) was set by IOM at $3.5 \mathrm{~g} / \mathrm{d}$ for adults aged 19 years and above (including pregnant or lactating adult women). In addition, UL were derived by IOM from the UL for adults and were set at $3 \mathrm{~g} / \mathrm{d}$ for adolescents (14-18 years) and at $2 \mathrm{~g} / \mathrm{d}$ (9-13 years) and $1 \mathrm{~g} / \mathrm{d}$ ( $1-8$ years) for children. The UL values were based on reported hypotension in a study on seven patients, and cholinergic effects and fishy body odour in four studies on patients, after oral administration of choline ${ }^{(5)}$. Until recently, it was difficult to calculate the dietary intake for choline, as little information was available on choline content in foods. Based on the consumption habits reported by thirty-two healthy adult volunteers and newly published choline content data, Fischer et $a l^{(6)}$ estimated for the first time in 2003 a mean choline intake of $6.7-8.4 \mathrm{mg} / \mathrm{kg}$ body weight per $\mathrm{d}$ for women and men, respectively. To stimulate choline intake assessment, the United States Department of Agriculture (USDA) developed a database that provides researchers and consumers with data about the choline content in foods ${ }^{(7)}$. First published in 2008, this database is being regularly updated ${ }^{(7,8)}$. Based on this database, the choline intake was estimated for the general population in the USA ${ }^{(9,10)}$, Taiwan ${ }^{(11)}$, New Zealand ${ }^{(12)}$ and also for a group of pregnant and lactating women in Canada ${ }^{(13)}$. Depending on the country, sex and age class, the mean choline intake was estimated between 222 and $415 \mathrm{mg} / \mathrm{d}^{(6,9-13)}$. Variability in nutrient intake estimates is commonly observed across country, sex and age class ${ }^{(14-16)}$. In Europe, no national intake estimates of choline are available yet. Estimating the choline intake in different European countries could provide insight into choline intake at a national level. In addition, ranges of choline intake between the different countries could be obtained for Europe. The aims of this study were to estimate the choline intake for different age classes by combining choline composition data from the USDA database with available and representative food consumption data from European countries and to characterise the main food groups contributing to the daily intake of choline.

\section{Methods}

\section{Food consumption data}

Food consumption data from the European Food Safety Authority (EFSA) European Comprehensive Food Consumption Database (Comprehensive Database) were used for the intake assessment. This database is the result of an agreement between the EFSA and European countries to pool national-level consumption data collected through representative dietary surveys carried out in each country. First published in 2010, this database is regularly updated when new dietary surveys become available ${ }^{(17,18)}$. At the end of 2014, the Comprehensive Database contained consumption data of about 67000 individuals originating from thirtythree surveys, representing eighteen European countries and covering all age classes from infants to very elderly people. Foods in the database are coded according to the FoodEx classification system, which consists of a food list containing approximately 2000 food items, organised in four levels of hierarchy ${ }^{(19)}$.

Out of the thirty-three surveys present in the Comprehensive Database, twelve were considered for this assessment. These surveys were selected because they corresponded to the most recent food consumption data collected in Europe and for which foods were described according to an upgraded version of FoodEx - FoodEx2. This version allows for a more precise description of foods than the previous one. In brief, FoodEx2 is still based on a main food list of 2673 entries, hereafter referred to as 'basic FoodEx 2 code'. In addition, a catalogue of twenty-eight properties (hereafter mentioned as 'facets') is available in order to describe characteristics of the foods, such as physical state (e.g. powder, purée-type, liquid), processing technology (e.g. boiling, frying, baking, drying) or fortification (e.g. fortified with vitamins only ${ }^{(19)}$. Such characteristics are important to be considered when assessing nutrient intake, because nutrient content may vary greatly depending on them. Consequently, surveys for which foods were not described at this level of detail in the Comprehensive Database were considered not fit for the purpose of nutrient intake assessment.

Table 1 presents the characteristics of each dietary survey. The countries included were Finland ${ }^{(20-22)}$, France ${ }^{(23)}$, Germany $^{(24,25)}$, Ireland ${ }^{(26)}$, Italy ${ }^{(27)}$, Latvia $^{(17)}$, The Netherlands ${ }^{(28)}$, Sweden ${ }^{(29)}$ and the $\mathrm{UK}^{(30)}$. Dietary surveys were conducted between 2000 and 2012. They were primarily conducted with the objective to monitor the nutrient intakes at the national level. The consumption habits were collected using 3-7-d food records, 24-h recalls performed on at least $2 \mathrm{~d}$ and 48 - $\mathrm{h}$ recalls. These dietary assessment methods have been reported to be valid methods to estimate the nutrient intake at a national level and are commonly used worldwide ${ }^{(31-34)}$. Across the countries, the age classes covered for the intake assessment were toddlers ( 1 to $\leq 3$ years old), 'other children' ( 3 to $\leq 10$ years old), adolescents (10 to $\leq 18$ years old), adults ( 18 to $\leq 65$ years old), elderly people ( 65 to $\leq 75$ years old) and very elderly people ( $\geq 75$ years old). These are the standard age classes retained to present nutrient intake and exposure levels in Europe, except infants ${ }^{(17)}$. Food consumption data were provided by four dietary surveys for toddlers, by seven dietary surveys for both 'other children' and adolescents, by eight dietary surveys for adults, by seven dietary surveys for elderly people and by five dietary surveys for very elderly people. Data on infants were not taken into account in this nutrient intake assessment due to limited quantification of human breast milk in the dietary surveys ${ }^{(20,24,27)}$. The Latvian survey ${ }^{(17)}$ focused only on pregnant women and adolescents.

Considering the methodological differences for the collection of consumption habits between the surveys, the surveys were not combined and no single European estimates were assessed in this study. Each survey data set is used separately and the resulting estimates cannot be interpreted in country-to-country 
Table 1. Characteristics of the twelve dietary surveys from the European Food Safety Authority Comprehensive European Food Consumption Database included in the choline intake assessment

\begin{tabular}{|c|c|c|c|c|c|c|}
\hline Countries & Dietary survey & Period $^{*}$ & Method & Days† & Number of subjectsł & Age range (years) \\
\hline Finland & DIPP_2000_2009 & 2000-2009 & Dietary record & 3 & 1250 & $1-6$ \\
\hline Finland & NWSSPP7_08 & $2007-2008$ & 48-h dietary recall & 4 & 306 & $13-15$ \\
\hline Finland & FINDIET2012 & 2012 & 48-h dietary recall & 2 & 1708 & $25-74$ \\
\hline France & INCA2 & $2006-2007$ & Dietary record & 7 & 4079 & $3-79$ \\
\hline Germany & EsKiMo & 2006 & Dietary record & 3 & 1228 & $6-11$ \\
\hline Germany & VELS & 2001-2002 & Dietary record & 6 & 641 & $1-4$ \\
\hline Ireland & NANS_2012 & 2008-2010 & Dietary record & 4 & 1500 & $18-90$ \\
\hline Italy & INRAN-SCAI 2005-06 & 2005-2006 & Dietary record & 3 & 3307 & $1-98$ \\
\hline Latvia & FC_PREGNANTWOMEN_2011 & 2011 & 24-h dietary recall & 2 & 1002 & $15-45$ \\
\hline The Netherlands & DNFCS_2007-2010 & $2007-2010$ & 24-h dietary recall & 2 & 3819 & $7-69$ \\
\hline Sweden & Riksmaten 2010 & 2010-2011 & Web record & 4 & 1797 & $18-80$ \\
\hline UK & NDNS-RollingProgrammeYears 1-3 & 2008-2011 & Dietary record & 4 & 3073 & $1-94$ \\
\hline
\end{tabular}

DIPP, type 1 Diabetes Prediction and Prevention survey; NWSSP, Nutrition and Well-being of Secondary School Pupils; FINDIET, National Dietary Survey of Finland; INCA, étude Individuelle Nationale de Consommations Alimentaires; EsKiMo, Ernährungstudie als KIGGS-Modul; VELS, Verzehrsstudie zur Ermittlung der Lebensmittelaufnahme von Säuglingen und Kleinkindern für die Abschätzung eines akuten Toxizitätsrisikos durch Rückstände von Pflanzenschutzmitteln; NANS, National Adult Nutrition Survey; INRANSCAI, Istituto Nazionale di Ricerca per gli Alimenti e la Nutrizione - Studio sui Consumi Alimentari in Italia; FC_PREGNANTWOMEN, food consumption of pregnant women in Latvia; DNFCS, Dutch National Food Consumption Survey; NDNS, National Diet and Nutrition Survey.

* Starting and ending years of the survey.

$\dagger$ Maximum number of reporting days per subject.

$\ddagger$ Number of subjects with at least 2 reporting days.

comparisons. Such approach is in line with the EFSA guidance on the use of the Comprehensive Database for exposure assessment $^{(17)}$. As nutrient intake estimates may vary across countries, sex and age ${ }^{(14-16)}$, the choline intake estimates for each dietary survey provide insight for the ranges of choline intake in Europe.

Consumption of dietary supplements was not taken into consideration in this study.

\section{Choline composition data}

No choline composition data are currently available within national food composition databases available in Europe. Choline content of foods considered in this intake assessment were, therefore, extracted from the National Nutrient Database for Standard Reference, release 26 of the $\operatorname{USDA}^{(7)}$ issued in November 2013. This database provides information on total choline content of US foodstuffs, calculated as the sum of five choline-contributing metabolites - free choline, glycerophosphocholine, phosphocholine, phosphatidylcholine and sphingomyelin. The USDA database also provided data on betaine content of foods, which were, however, not taken into account in this intake assessment. For chemical analysis, choline compounds were extracted, partitioned into organic and aqueous phases using methanol and chloroform and analysed directly by liquid chromatography electrospray ionization-isotope dilution $\mathrm{MS}^{(35)}$. The overall quality and reliability of the analytical results was assessed as good by the $\mathrm{USDA}^{(8)}$. A total of 4467 values were extracted from the USDA database, $26 \%$ corresponding to analytical results, $73 \%$ being calculated or imputed and $1 \%$ being assumed at 0 . Choline content ranged from $0 \mathrm{mg} / 100 \mathrm{~g}$ of food (e.g. alcoholic beverages, water, candies) to $2403.3 \mathrm{mg} / 100 \mathrm{~g}$ (egg yolk, dried).

The nutrient composition food list considered in this assessment was created by re-coding the USDA nutrient composition food list, which is based on the LanguaL food description thesaurus, according to the FoodEx2 classification system of the $\operatorname{EFSA}^{(19,36)}$.

The first challenge was the difference in the level of detail between the USDA nutrient composition food list and the FoodEx 2 classification system. For example, a meat type such as beef appeared in the USDA nutrient composition food list about 680 times and was described according to the part of the animal (chuck, rib, short loin, round, flank, etc.) and the processing method (raw, baked, cooked, roasted, etc.). The FoodEx2 classification system, however, does not take the different parts of the animal into account and contains only one type of beef meat (bovine fresh meat) among the basic FoodEx2 codes, whereas the processing method is described as a facet. To avoid exclusion of major contributors to choline intake from the intake assessment, the choline composition data of all parts of the animal from the USDA nutrient composition food list were averaged for each processing method, and then coded with the basic FoodEx 2 code for beef meat including a relevant processing facet descriptor (raw, baked, cooked, roasted, etc.). The same type of averaging was carried out for the following food items: turkey, veal, pork, lamb, chicken, game meat, infant formula (powder or liquid) and ice cream (milk or water based). A total of 1610 food items of the USDA nutrient composition food list were averaged to form 107 equivalent food items coded according to FoodEx2.

Another challenge concerned commercial food products such as breakfast cereals and baby foods. In the USDA nutrient composition food list, such foods were described according to their brand names, whereas in the FoodEx 2 classification system they are classified according to their main ingredient and brand names are not taken into account. In order to include such products in the intake assessment, the ingredient list of the US commercial product was screened on the internet (e.g. company website) and further coded according to its main ingredient - for example, the breakfast cereal product 'General 
Mills, Kix' (General Mills, Inc.) was coded as 'processed maizebased flakes' in the FoodEx2 classification system. A total of 486 food items of the USDA nutrient composition food list were coded according to their main ingredient.

Finally, some food items present in the USDA nutrient composition food list, such as chrysanthemum garland or lotus root, had no corresponding code in the FoodEx 2 classification system. When no equivalent could be found, the food item was excluded from the nutrient composition food list considered in this assessment. This included a total of $280(6 \%)$ individual food items out of 4467 items present in the USDA nutrient composition list.

In the end, choline composition was available for 2684 food items of the FoodEx2 system for the intake assessment.

\section{Matching composition and consumption data}

The linking of the consumed foods with the choline composition values was carried out following three types of matching:

1. 'Exact match', the food consumed had an equivalent in the composition data matching the basic FoodEx 2 code and all the available facet descriptors. The value provided (or an average if there were several corresponding foods) was used.

2. 'Partial match', the food consumed had an equivalent in the composition data matching the basic FoodEx2 code and a selection of four FoodEx 2 facet descriptors relevant for this intake assessment: processing technology (e.g. coating, slicing, roasting), vitamin and mineral fortification agent, physical state (e.g. powder, liquid, purée) and qualitative information (e.g. reduced sugar, reduced salt, full fat). The value provided (or an average if there were several corresponding foods) was used.

3. 'Default match', the food consumed had an equivalent in the composition data regarding only the basic FoodEx2 code. The average of all the foods with the same basic FoodEx2 code in the composition data was used.

When no equivalent basic FoodEx 2 code could be found in the composition food list (i.e. the composition value was missing), an extrapolation from a related FoodEx 2 code was considered. The substitute code was either a (existing) FoodEx2 code (e.g. the lacking choline content of 'oat grains' was replaced by that of the code 'oat groats') or an average of several basic codes at a higher level of the FoodEx2 hierarchy (e.g. a missing choline value for 'undefined mixed poultry fresh meat' was replaced with the average of choline values in the group of 'poultry fresh meat'). Such extrapolations were carried out only for foods corresponding to at least one of the following criteria:

- Foods frequently consumed (number of consumption events $>2000$ considering the entire consumption data set, e.g. the missing FoodEx 2 code of the frequently consumed 'salami-type sausage' is replaced by the FoodEx 2 code of 'chorizo and similar')

- Foods consumed in a considerable 'large' amount (defined here as total consumption of the food by 1000 individuals of the database $>100 \mathrm{~kg} / \mathrm{d}$, e.g. the missing FoodEx 2 code of the widely consumed 'cows' skimmed milk' is replaced by the FoodEx 2 code of 'cows' semi-skimmed milk').

- Foods from a food group containing similar foods with 'high' choline content (defined as among the highest $10 \%$ in the choline composition data set, e.g. the missing FoodEx2 code of the high in choline content food 'cream powder' is replaced by the FoodEx2 code of 'milk powder').

- Foods belonging to one of the main food groups contributing to choline intake based on a preliminary analysis.

The remaining food items such as garlic purée or cloudberries were not taken into account in the intake assessment (i.e. choline content was considered as 0 ).

Table 2 details the typology of matching between the consumption and composition data for each survey considered in this assessment and for the entire consumption database. Out of the 23020 FoodEx 2 codes available in the entire consumption database, 118 (1\%) had an 'exact match', 1789 (8\%) a 'partial match' and 12003 (52\%) a 'default match' in the composition data set. A choline value could be extrapolated for 5333 (23\%) other FoodEx2 codes. The remaining 3777 Foodex 2 codes (16\%) were assigned a choline content of 0 for this intake assessment. This typology was similar across the different surveys.

\section{Choline intake calculations}

Choline intake was calculated at the individual level by multiplying, for each food item, the average consumption level by the corresponding choline content and summing up the respective intakes throughout the diet of each subject. The mean as well as the 5th, 50th and 95th percentiles of intake were derived at the population level for each survey, age class and sex. Results were expressed as total choline in $\mathrm{mg} / \mathrm{d}$. Means were compared with the AI and 95th percentiles with the UL as set by the $\mathrm{IOM}^{(5)}$. The contribution of the twenty-one main food groups (FoodEx2 level 1) ${ }^{(19)}$ to the mean total choline intake was determined, for each age class, sex and survey, as the ratio between the mean choline intake resulting from the consumption of the food group and the mean total choline intake and expressed as percentage contribution. Further, for each age class and sex, the lowest and highest percentage contributions of the main food groups found across the surveys were retained. Within the main food groups, the highest contributing food item (FoodEx2 level 2) ${ }^{(19)}$ was described. The calculations were carried out using SAS software (SAS Enterprise Guide $^{\circledR}$ 5.1, 2013).

\section{Results}

\section{Choline intake}

Estimated choline intakes for males and females per age class and survey are presented in Table 3. Average choline intake ranged from 151 to $210 \mathrm{mg} / \mathrm{d}$ among toddlers (1-3 years) and from 177 to $304 \mathrm{mg} / \mathrm{d}$ among 'other children' ( 3 to $<10$ years). These values were below the corresponding AI, as defined by the $\mathrm{IOM}^{(5)}$, for toddlers in almost all the surveys (except for 
males in the UK and Italy). For 'other children' ( 3 to $<10$ years), the average intake was below the AI of children (4-8 and 9-13 years) in one-third of the surveys. The 5th percentile of choline intake ranged from 79 to $132 \mathrm{mg} / \mathrm{d}$ among toddlers and from 106 to $186 \mathrm{mg} / \mathrm{d}$ among 'other children'. The 95th percentile choline intakes ranged from 242 to $313 \mathrm{mg} / \mathrm{d}$ among toddlers and from 263 to $487 \mathrm{mg} / \mathrm{d}$ among 'other children'. Toddlers were below the UL of $1 \mathrm{~g} / \mathrm{d}$ and 'other children' were below the UL of $1-2 \mathrm{~g} / \mathrm{d}$ ( $4-8$ and $9-13$ years) as defined by the $\mathrm{IOM}^{(5)}$.

Among males, the average intake estimates ranged from 309 to $373 \mathrm{mg} / \mathrm{d}$ in adolescents (10 to <18 years), from 357 to $468 \mathrm{mg} / \mathrm{d}$ in adults, from 358 to $450 \mathrm{mg} / \mathrm{d}$ in elderly people and from 332 to $444 \mathrm{mg} / \mathrm{d}$ in very elderly people. These values were all below the $\mathrm{AI}^{(5)}$. The 5 th percentile of choline intake ranged from 162 to $208 \mathrm{mg} / \mathrm{d}$ among adolescents and from 178 to $251 \mathrm{mg} / \mathrm{d}$ among adults, elderly and very elderly people. The 95 th percentile choline intakes, ranging from 483 to $572 \mathrm{mg} / \mathrm{d}$ among adolescents ( 10 to $<18$ years old) and from 474 to $773 \mathrm{mg} / \mathrm{d}$ among adults, elderly and very elderly people, were below their UL of $3 \mathrm{~g} / \mathrm{d}$ (adolescents $14-18$ years) and $3.5 \mathrm{~g} / \mathrm{d}$ (adults $>19$ years). Among females, average intake estimates ranged from 244 to $336 \mathrm{mg} / \mathrm{d}$ in adolescents (10 to <18 years), from 291 to $374 \mathrm{mg} / \mathrm{d}$ in adults, from 284 to $377 \mathrm{mg} / \mathrm{d}$ in elderly people and from 269 to $404 \mathrm{mg} / \mathrm{d}$ in very elderly people. As for the male population groups, they were below their corresponding $\mathrm{AI}^{(5)}$. The 5 th percentile of choline intake ranged from 122 to $175 \mathrm{mg} / \mathrm{d}$ among adolescents and from 138 to $633 \mathrm{mg} / \mathrm{d}$ among adults, elderly and very elderly people. The 95th percentile choline intakes, ranging from 395 to $744 \mathrm{mg} / \mathrm{d}$ among adolescents (10 to $<18$ years) and from 391 to $633 \mathrm{mg} / \mathrm{d}$ among adults, elderly and very elderly people, were also below the corresponding UL values.

Among pregnant women from the Latvian survey, the average choline intake was $336 \mathrm{mg} / \mathrm{d}$ in the adolescent age class and was $356 \mathrm{mg} / \mathrm{d}$ in the adult age class. These were below the AI of $450 \mathrm{mg} / \mathrm{d}$ defined for pregnant women or adolescents ${ }^{(5)}$. The 5th percentile of choline intake in Latvian adult pregnant women was $200 \mathrm{mg} / \mathrm{d}$, whereas the 95 th percentile was $592 \mathrm{mg} / \mathrm{d}$.

Overall, choline intake was higher among males compared with females, mainly due to larger quantities of food consumed per day. Indeed, when looking at intake per unit of energy intake (mg/MJ), no difference between the intakes of males and females was observed (data not shown).

\section{Main food contributors}

The lowest and highest percentage contributions of the eight main contributing food groups (highest contribution $>10 \%$ ) to total choline intake across available surveys are presented per age class in Table 4 for males and in Table 5 for females. The main food group contributor to choline daily intake was 'meat and meat products', representing $>10 \%$ and up to $37 \%$ of the total intake in all population groups. Other main contributing food groups were milk, grain, egg and their derived products, composite dishes and fish and seafood, representing, respectively, 7-40, 6-22, 3.5-23, 0.4-19 and 0.6-14\% over all age groups. Within these main food groups, the detailed 
Table 3. Total choline intake estimates among males and females in twelve different European surveys according to age class and country (Number of subjects; medians and 5th and 95th percentiles)

\begin{tabular}{|c|c|c|c|c|c|c|c|c|c|c|c|c|}
\hline \multirow[b]{2}{*}{ Age class } & \multirow[b]{2}{*}{ Countries } & \multirow[b]{2}{*}{ Survey } & \multicolumn{5}{|c|}{ Male intakes $(\mathrm{mg} / \mathrm{d})$} & \multicolumn{5}{|c|}{ Female intakes $(\mathrm{mg} / \mathrm{d})$} \\
\hline & & & $n$ & Average & Median & P5 & P95 & $n$ & Average & Median & P5 & P95 \\
\hline \multirow[t]{4}{*}{ Toddlers ( 1 to $\leq 3$ years old) } & Finland & DIPP_2001_2009 & 245 & 180 & 178 & 91 & 279 & 255 & 171 & 165 & 79 & 266 \\
\hline & Germany & VELS & 174 & 162 & 155 & 90 & 251 & 174 & 151 & 147 & 90 & 242 \\
\hline & Italy & INRAN-SCAI 2005-06 & 20 & 210 & 210 & * & * & 16 & 199 & 191 & * & * \\
\hline & UK & NDNS-RollingProgrammeYears1-3 & 107 & 204 & 200 & 114 & 313 & 78 & 181 & 176 & 107 & 277 \\
\hline \multirow[t]{7}{*}{ Other children ( 3 to $\leq 10$ years old) } & Finland & DIPP_2001_2009 & 381 & 285 & 277 & 162 & 417 & 369 & 256 & 249 & 154 & 364 \\
\hline & France & INCA $\overline{2}$ & 239 & 276 & 268 & 159 & 403 & 243 & 245 & 237 & 150 & 353 \\
\hline & Germany & VELS & 146 & 194 & 187 & 116 & 299 & 147 & 177 & 172 & 106 & 263 \\
\hline & Germany & EsKiMo & 426 & 304 & 291 & 186 & 467 & 409 & 272 & 260 & 160 & 416 \\
\hline & Italy & INRAN-SCAI 2005-06 & 94 & 292 & 270 & 163 & 474 & 99 & 296 & 286 & 148 & 487 \\
\hline & The Netherlands & DNFCS_2007-2010 & 231 & 292 & 276 & 145 & 471 & 216 & 273 & 256 & 155 & 411 \\
\hline & UK & NDNS-RollingProgrammeYears1-3 & 326 & 243 & 231 & 151 & 370 & 325 & 234 & 225 & 133 & 367 \\
\hline \multirow[t]{6}{*}{ Adolescents (10 to $\leq 18$ years old) } & Finland & NWSSP07_08 & 136 & 373 & 362 & 208 & 572 & 170 & 292 & 286 & 155 & 469 \\
\hline & France & INCA2 & 449 & 332 & 330 & 189 & 517 & 524 & 267 & 259 & 158 & 402 \\
\hline & Germany & EsKiMo & 197 & 316 & 302 & 186 & 488 & 196 & 295 & 282 & 172 & 464 \\
\hline & Italy & INRAN-SCAI 2005-06 & 108 & 368 & 351 & 190 & 561 & 139 & 310 & 294 & 161 & 484 \\
\hline & The Netherlands & DNFCS_2007-2010 & 566 & 353 & 338 & 189 & 569 & 576 & 291 & 279 & 170 & 458 \\
\hline & UK & NDNS-RollingProgrammeYears1-3 & 340 & 309 & 294 & 162 & 483 & 326 & 244 & 232 & 122 & 395 \\
\hline Adolescents (pregnant) & Latvia & FC_PREGNANTWOMEN_2011 & - & - & - & - & - & 12 & 336 & 288 & * & * \\
\hline \multirow[t]{7}{*}{ Adults ( 18 to $\leq 65$ years old) } & Finland & FINDIET2012 & 585 & 450 & 425 & 229 & 749 & 710 & 344 & 327 & 177 & 578 \\
\hline & France & INCA2 & 936 & 370 & 362 & 206 & 565 & 1340 & 291 & 283 & 162 & 440 \\
\hline & Ireland & NANS_2012 & 634 & 461 & 443 & 251 & 718 & 640 & 318 & 314 & 166 & 485 \\
\hline & Italy & INRAN-SCAI 2005-06 & 1068 & 357 & 341 & 187 & 587 & 1245 & 293 & 282 & 153 & 463 \\
\hline & The Netherlands & DNFCS_2007-2010 & 1023 & 448 & 425 & 241 & 707 & 1034 & 334 & 317 & 185 & 543 \\
\hline & Sweden & Riksmaten 2010 & 623 & 468 & 442 & 235 & 773 & 807 & 374 & 356 & 186 & 631 \\
\hline & UK & NDNS-RollingProgrammeYears1-3 & 560 & 407 & 385 & 178 & 697 & 706 & 294 & 282 & 145 & 478 \\
\hline Adults (pregnant women) & Latvia & FC_PREGNANTWOMEN_2011 & - & - & - & - & - & 990 & 356 & 330 & 200 & 592 \\
\hline \multirow[t]{7}{*}{ Elderly people (65 to $\leq 75$ years old) } & Finland & FINDIET2012 & 210 & 400 & 375 & 187 & 738 & 203 & 317 & 297 & 152 & 493 \\
\hline & France & INCA2 & 111 & 379 & 380 & 218 & 525 & 153 & 293 & 289 & 167 & 446 \\
\hline & Ireland & NANS_2012 & 72 & 433 & 421 & 225 & 679 & 77 & 334 & 321 & 182 & 527 \\
\hline & Italy & INRAN-SCAI 2005-06 & 133 & 358 & 344 & 200 & 566 & 157 & 284 & 283 & 144 & 443 \\
\hline & The Netherlands & DNFCS_2007-2010 & 91 & 413 & 400 & 220 & 639 & 82 & 331 & 321 & 144 & 474 \\
\hline & Sweden & Riksmaten 2010 & 127 & 450 & 423 & 219 & 750 & 168 & 377 & 357 & 195 & 633 \\
\hline & UK & NDNS-RollingProgrammeYears1-3 & 75 & 404 & 398 & 213 & 585 & 91 & 317 & 315 & 193 & 435 \\
\hline \multirow[t]{5}{*}{ Very elderly people ( $\geq 75$ years old) } & France & INCA2 & 40 & 360 & 348 & * & * & 44 & 285 & 273 & * & * \\
\hline & Ireland & NANS_2012 & 34 & 388 & 380 & * & * & 43 & 304 & 287 & * & * \\
\hline & Italy & INRAN-SCAI 2005-06 & 69 & 335 & 320 & 211 & 497 & 159 & 269 & 269 & 138 & 391 \\
\hline & Sweden & Riksmaten 2010 & 42 & 444 & 414 & * & * & 30 & 404 & 374 & * & * \\
\hline & UK & NDNS-RollingProgrammeYears1-3 & 56 & 332 & 317 & * & * & 83 & 308 & 301 & 215 & 413 \\
\hline
\end{tabular}

-, No data; DIPP, type 1 Diabetes Prediction and Prevention survey; VELS, Verzehrsstudie zur Ermittlung der Lebensmittelaufnahme von Säuglingen und Kleinkindern für die Abschätzung eines akuten Toxizitätsrisikos durch Rückstände von Pflanzenschutzmitteln; INRAN-SCAl, Istituto Nazionale di Ricerca per gli Alimenti e la Nutrizione - Studio sui Consumi Alimentari in Italia; NDNS, National Diet and Nutrition Survey; INCA, étude Individuelle Nationale de
Consommations Alimentaires; EsKiMo, Ernährungstudie als KIGGS-Modul; DNFCS, Dutch National Food Consumption Survey; NWSSP, Nutrition and Well-being of Secondary School Pupils; FC PREGNANTWOMEN, food consumption of pregnant women in Latvia; FINDIET, National Dietary Survey of Finland; NANS, National Adult Nutrition Survey.

* 5 th or 95 th percentile intakes calculated over a number of subjects $<60$ require cautious interpretation as the results may not be statistically robust ${ }^{(17)}$, and therefore for these dietary surveys/age classes the 5 th and 95 th percentile estimates are not be presented in the intake results. 
Table 4. Lowest and highest percentage contributions of the main contributing food groups to the mean total choline daily intake across available surveys per each age class, in males

\begin{tabular}{lccccc}
\hline Food groups & $\begin{array}{c}\text { Toddlers }(1 \text { to } \leq 3 \\
\text { years) }(\%)\end{array}$ & $\begin{array}{c}\text { Other children (3 to } \\
\leq 10 \text { years) }(\%)\end{array}$ & $\begin{array}{c}\text { Adolescents (10 to } \\
\leq 18 \text { years) (\%) }\end{array}$ & $\begin{array}{c}\text { Adults (18 to } \leq 65 \\
\text { years) }(\%)\end{array}$ & $\begin{array}{c}\text { Elderly }(65 \text { to } \leq 75 \text { Very elderly }(\geq 75 \\
\text { years) }(\%)\end{array}$ \\
\hline years) (\%)
\end{tabular}

- , No intake recorded.

Table 5. Lowest and highest percentage contributions of the main contributing food groups to the mean total choline daily intake across available surveys per each age class, in females

\begin{tabular}{|c|c|c|c|c|c|c|}
\hline Food groups & $\begin{array}{c}\text { Toddlers }(1 \text { to } \leq 3 \\
\text { years) }(\%)\end{array}$ & $\begin{array}{l}\text { Other children ( } 3 \text { to } \\
\leq 10 \text { years) }(\%)\end{array}$ & $\begin{array}{l}\text { Adolescents (10 to } \\
\leq 18 \text { years) }(\%)\end{array}$ & $\begin{array}{c}\text { Adults (18 to } \leq 65 \\
\text { years) }(\%)\end{array}$ & $\begin{array}{c}\text { Elderly (65 to } \leq 75 \\
\text { years) (\%) }\end{array}$ & $\begin{array}{c}\text { Very elderly ( } \geq 75 \\
\text { years) }(\%)\end{array}$ \\
\hline Composite dishes & $0.4-12.6$ & $0.2-15 \cdot 8$ & $0.7-18.7$ & $0.4-16.6$ & $0.5-14.7$ & $0.4-18.5$ \\
\hline Eggs and egg products & $3.9-13 \cdot 5$ & $4 \cdot 3-22 \cdot 8$ & $3 \cdot 2-20 \cdot 4$ & $6 \cdot 1-18 \cdot 7$ & $8 \cdot 1-18 \cdot 1$ & $8-21 \cdot 1$ \\
\hline $\begin{array}{l}\text { Fish, seafood, amphibians, } \\
\text { reptiles and invertebrates }\end{array}$ & $1.4-14.4$ & $0.6-7.4$ & $0.9-10.1$ & $2.5-10.6$ & $2 \cdot 8-11$ & $5 \cdot 9-9 \cdot 7$ \\
\hline $\begin{array}{l}\text { Food products for young } \\
\text { population }\end{array}$ & $3 \cdot 9-12$ & $<0.1-0.4$ & $<0.1-0.1$ & $<0.1$ & - & $<0 \cdot 1$ \\
\hline $\begin{array}{l}\text { Grains and grain-based } \\
\text { products }\end{array}$ & $6-18$ & $6 \cdot 8-21.5$ & $8 \cdot 9-22 \cdot 1$ & $9 \cdot 1-16 \cdot 5$ & $7 \cdot 9-17 \cdot 3$ & $9-17 \cdot 2$ \\
\hline Meat and meat products & $13 \cdot 8-20 \cdot 7$ & $16 \cdot 7-29 \cdot 1$ & $20 \cdot 8-32 \cdot 4$ & $21 \cdot 6-31 \cdot 8$ & $18 \cdot 5-28 \cdot 6$ & $15 \cdot 5-29 \cdot 7$ \\
\hline $\begin{array}{l}\text { Milk and dairy products } \\
\text { (excluding human milk) }\end{array}$ & $24 \cdot 8-41 \cdot 2$ & $14-40 \cdot 5$ & $11 \cdot 7-31 \cdot 5$ & $10 \cdot 8-23 \cdot 7$ & $10 \cdot 4-24 \cdot 4$ & $12 \cdot 2-18 \cdot 8$ \\
\hline
\end{tabular}

- , No intake recorded ${ }^{(4)}$.

contributing foods (FoodEx2 level 2) were animal fresh meat, bread and similar products, milk, whey and cream, unprocessed eggs, ready-to-eat meals (excluding soups and salads) and fish. Food groups with little contribution (highest contribution $<10$ \%) to total choline intake (data not shown in Tables 4 and 5) were water-based beverages (0-0.6\%), alcoholic beverages $(0-9 \cdot 8 \%)$, coffee, cocoa, tea and infusions $(0 \cdot 1-5 \cdot 1 \%)$, fats and oils $(0 \cdot 2-1 \cdot 2 \%)$, sugar and confectionery $(0 \cdot 1-2 \cdot 3 \%)$, legumes, nuts and oilseeds $(0.4-3.6 \%)$, products of non-standard diets and food imitates (0-2.3\%), fruits (1.1-6\%), vegetables (1.9-8.4\%), fruit and vegetable juices $(0 \cdot 2-2 \cdot 9 \%)$, starchy roots and tubers $(2 \cdot 6-7 \cdot 9 \%)$, additives $(0-0.3 \%)$ and seasoning $(0 \cdot 1-1.5 \%)$. The food contributors were the same in males and females, and the percentage contribution was in the same order of magnitude (e.g. for 'meat and meat products' $22 \cdot 8-37 \cdot 1 \%$ for adult males and $21 \cdot 6-31.8 \%$ for adult females). Similarity in the contribution of food groups for the different age classes was found in the different surveys (data not shown).

\section{Discussion}

To our knowledge, this study is the first to estimate the choline intake for different age classes in males and females at the European level. This study was based on detailed, high-quality and partially harmonised food consumption data available at the European level. Indeed, the twelve dietary surveys considered in this study were mostly in line with the requirements defined by the EFSA for the collection of consumption data for risk assessment $^{(34)}$. The surveys were representative of the general population or of specific population groups such as pregnant women; the consumption data have been collected at the individual level, with at least 2 reporting days per subject; subject characteristics involved the same descriptors; and foods were described using the same food classification system (FoodEx2). Surveys were based either on dietary records from 3 to $7 \mathrm{~d}$, or on 24- or 48-h recalls, repeated at least twice. Considering the main sources of choline in the diet - meat, milk, grains, eggs and their derived products - which are commonly consumed foods in Europe, the data collected with such instruments are considered as fit for purpose, without considering the inputs from an FFQ targeting scarcely consumed food. However, due to the different methodologies between the surveys, the resulting estimates cannot be interpreted in country-to-country comparisons. Harmonisation of methodologies for collecting food consumption surveys are underway, but fully harmonised consumption data at the European level are not expected before $2020^{(37)}$. At the time of this study, it was not known whether choline was common in the supplements consumed by the European population. 
Choline intake from consumption of supplements has consequently not been taken into account, which may have led to an underestimation of the total intake.

The findings of this study are in line with the limited number of studies available from other jurisdictions ${ }^{(6,9-13,38,39)}$. For example, information obtained from the National Health and Nutrition Examination Survey in the USA showed mean choline intake estimates of $415 \mathrm{mg} / \mathrm{d}$ for adult males and $279 \mathrm{mg} / \mathrm{d}$ for adult females (20-69 years) ${ }^{(10)}$. In Taiwan, mean choline intake was estimated at $372 \mathrm{mg} / \mathrm{d}$ for adult males and $265 \mathrm{mg} / \mathrm{d}$ for adult females (18-64 years) ${ }^{(11)}$. Mean estimates for males in the USA and Taiwan fall thereby in the range of the mean total choline daily intake estimated in this study for European adult men aged $18-65$ years $(357-468 \mathrm{mg} / \mathrm{d})$. For females, the mean estimates in the USA and Taiwan are below the mean total choline daily intake estimated for European adult women in this study (291-374 mg/d). In New Zealand, a study on adult females (18-40 years) had, however, an average choline intake of $316 \mathrm{mg} / \mathrm{d}$, and are thereby similar to the European adult females $^{(12)}$. In a recent Canadian study ${ }^{(13)}$, mean total choline intake in women (17-45 years) during pregnancy was estimated at $347 \mathrm{mg} / \mathrm{d}$, which is in the same range as the mean total intake estimated in this study for pregnant Latvian women and adolescents (336-356 mg/d). Nevertheless, direct comparability of choline intake estimates from different surveys available in the literature should be carried out with caution. Even though all the countries ${ }^{(10-13)}$ based their choline intake assessments on the composition data from the USDA Nutrient Database, the usage of different releases of this database may have resulted in variation in choline intake estimates. Especially, an increase in the content of choline for some foods was observed in a new release of the USDA nutrient composition database compared with a previous release published in 2008. For example, a whole raw egg in release 26 published in $2013^{(7)}$ contains $293.8 \mathrm{mg}$ choline/ $100 \mathrm{~g}$, whereas it contained $250 \mathrm{mg}$ choline $/ 100 \mathrm{~g}$ in release 2 published in $2008^{(8)}$. Moreover, differences in dietary survey methodology (age classes, number of reporting days, method for data collection) and nutrient intake modelling (i.e. usual intake assessment $v$. daily intake assessment) may explain the differences in intake estimates published in the literature and the ones estimated in this study. Furthermore, the dietary surveys used in this study have been studied to assess nutrient intakes at the national level, but were not validated for the assessment of dietary choline. To obtain more refined choline intake estimates in the future, it is recommended to validate dietary choline in national surveys.

In this study, the foods contributing highly to the mean daily intake of choline from the diet were meat, milk, grain, egg and their derived products, composite dishes and fish. The contribution of food to choline intake was similar for both sexes. Consistency in the main choline contributors was found when compared with published data ${ }^{(9,11-13,38)}$. For example, in New Zealand, a study on adult women found eggs, red meat, milk and bread as major food contributors to mean total choline daily intake $^{(12)}$. Main food group contributors in the US population were meat, poultry and fish, grain-based mixed meals, dairy and eggs ${ }^{(9)}$. Any difference in the contribution to the total daily choline intake could be explained by differences in consumption habits in population groups or by the difference in the definition of food groups ${ }^{(11)}$. For example, eggs were found to be the first contributor of choline intake in the adult Taiwanese population, whereas they were the third contributor in the adult US population $^{(11,38)}$. Nevertheless, an agreement on the major contribution of meat, milk, eggs, grain-based products, composite dishes and fish among the different population groups was found.

The main limitation of this study is related to the absence of choline composition data of European foods. The choline composition data from the USDA database considered in this assessment may not adequately reflect the choline content in foods as purchased and as consumed in Europe. Indeed, choline content can differ due to variations in formulation by manufacturers, different recipes as well as differences in the choline content of individual ingredients ${ }^{(9)}$. Practices of fortification may also be different between the USA and the different European countries taken into account in this study. For example, in the USA, choline is listed on the food additive list of the Food and Drug Administration ${ }^{(40)}$, and in Europe fortification is regulated at a national level where it depends on the country, whether it is added to the food or not ${ }^{(41)}$. In addition, inaccuracies may have occurred in mapping the food composition data from the USDA composition food list according to the FoodEx2 food classification system used in the European food consumption data, especially for foods described by their brand name in the USDA database and foods that are not described at the same level of precision in the FoodEx2 system compared with LanguaL. For example, the averaging of the meat types could have led to misleading results if choline content had been different for the different parts of the animal according to the USDA database ${ }^{(7)}$. However, in meat, little variability was observed in the choline content of the different parts of the animal. Differences in choline content were mainly observed between the different processing technologies (not processed, cooked, roasted, etc.), and these factors were taken into account in the intake assessment. Finally, a number of foods present in the European food consumption data considered in this study had no direct match with the composition data used. For half of them, corresponding to the most consumed foods and/or foods with highest choline content, the missing value was replaced by a value found in a similar food or at the food group level. For the remaining foods, choline contents of 0 were assumed. All these assumptions may have led to underestimation or overestimation of the true total choline intake in the European population.

\section{Conclusion}

To our knowledge, this is the first study to provide choline intake estimates for the European population. In most of the population groups considered, the average choline intake was found to be below the AI set in 1998 by the IOM in the USA. Given the definition of $\mathrm{AI}$, no conclusion can be drawn regarding the adequacy of choline intake. These results improve the knowledge about choline intake in Europe, which might be considered for risk management and to initiate further data collections to obtain refined estimates. Especially, in order to improve the quality of the estimates, it is recommended to measure the choline content in the main contributing food items, as available in the European market or in duplicate studies. 


\section{Acknowledgements}

The authors are grateful to Joseph Shavila (Food Standards Agency, UK) for providing UK consumption data used in this study.

The authors did not receive any funding for this study.

The authors' contribution are as follows: M. C. O., G. B. M. M., O. L., S. M. V., C. T., L. D'. A., I. M., C. D. and I. S. provided consumption data for the study; F. B. C. V. analysed the composition data and performed the intake assessment; S. I. and L. M. V. assisted with the preparation and interpretation of the data; F. H. assisted with the intake modelling; F. B. C. V. and F. H. wrote the manuscript; F. H. has the primarily responsibility for the final content of the manuscript. All the authors read and approved the final version of the manuscript.

None of the authors has any conflicts of interest to declare.

\section{References}

1. Zeisel SH, Da Costa KA, Franklin PD, et al. (1991) Choline, an essential nutrient for humans. FASEB J 5, 2093-2098.

2. Zeisel SH \& Blusztajn JK (1994) Choline and human nutrition. Annu Rev Nutr 14, 269-296.

3. Buchman AL, Dubin MD, Moukarzel AA, et al. (1995) Choline deficiency: a cause of hepatic steatosis during parenteral nutrition that can be reversed with intravenous choline supplementation. Hepatology 22, 1399-1403.

4. Fischer LM, daCosta KA, Kwock L, et al. (2007) Sex and menopausal status influence human dietary requirements for the nutrient choline. Am J Clin Nutr 85, 1275-1285.

5. Institute of Medicine (1998) Dietary Reference Intakes for Thiamin, Riboflavin, Niacin, Vitamin $B_{6}$, Folate, Vitamin $B_{12}$, Pantothenic Acid, Biotin, and Choline. Washington, DC: National Academies Press.

6. Fischer LM, Scearce JA, Mar MH, et al. (2005) Ad libitum choline intake in healthy individuals meets or exceeds the proposed adequate intake level. J Nutr 135, 826-829.

7. United States Department of Agriculture Agricultural Research Service (2013) USDA National Nutrient Database for Standard Reference, release 26. http://ndb.nal.usda.gov/ndb/nutrients/ report $/$ nutrientsfrm? $\max =25 \&$ offset $=0$ \&totCount $=0$ \&nutrient 1 $=421 \&$ nutrient $2=\&$ nutrient $3=\&$ subset $=0 \& f g=\&$ sort $=$ f \&measureby $=\mathrm{g}$ (accessed February 2014).

8. United States Department of Agriculture (2008) USDA Database for the Choline Content of Common Foods. Release 2. Beltsville, MD: US Department of Agriculture.

9. United States Department of Agriculture Agricultural Research Service (2011) Dietary intakes of choline, what we eat in America, NHANES 2007-2008. http://www.ars.usda.gov/ SP2UserFiles/Place/12355000/pdf/DBrief/9_choline_intakes_ 0708.pdf (accessed May 2014)

10. United States Department of Agriculture Agricultural Research Service (2012) Nutrient intakes from food: mean amounts consumed per individual, by gender and age, what we eat in America, NHANES 2009-2010. http://www.ars.usda.gov/SP2UserFiles/ Place/12355000/pdf/0910/Table_1_NIN_GEN_09.pdf （accessed May 2014).

11. Chu DM, Wahlqvist ML, Chang HY, et al. (2012) Choline and betaine food sources and intakes in Taiwanese. Asia Pac J Clin Nutr 21, 547-557.

12. Mygind VL, Evans SE, Peddie MC, et al. (2013) Estimation of usual intake and food sources of choline and betaine in New Zealand reproductive age women. Asia Pac J Clin Nutr 22, 319-324.
13. Lewis ED, Subhan FB, Bell RC, et al. (2014) Estimation of choline intake from $24 \mathrm{~h}$ dietary intake recalls and contribution of egg and milk consumption to intake among pregnant and lactating women in Alberta. Br J Nutr 112, 112-121.

14. Slimani N, Fahey M, Welch AA, et al. (2002) Diversity of dietary patterns observed in the European Prospective Investigation into Cancer and Nutrition (EPIC) project. Public Health Nutr 5, 1311-1328.

15. Doets EL, de Wit LS, Dhonukshe-Rutten RA, et al. (2008) Current micronutrient recommendations in Europe: towards understanding their differences and similarities. Eur J Nutr $\mathbf{4 7}$, $17-40$.

16. Tabacchi G, Wijnhoven TM, Branca F, et al. (2009) How is the adequacy of micronutrient intake assessed across Europe? A systematic literature review. Br J Nutr 101, S29-S36.

17. European Food Safety Authority (2011a) Use of the EFSA Comprehensive European Food Consumption Database in exposure assessment. EFSA J 9, 2097.

18. Merten C, Ferrari P, Bakker M, et al. (2011) Methodological characteristics of the national dietary surveys carried out in the European Union as included in the European Food Safety Authority (EFSA) Comprehensive European Food Consumption Database. Food Addit Contam Part A Chem Anal Control Expo Risk Assess 28, 975-995.

19. European Food Safety Authority (2011b) Report on the development of a Food Classification and Description System for exposure assessment and guidance on its implementation and use. EFSA J 9, 2489.

20. Helldan A, Raulio S, Kosola M, et al. (2013) The National FINDIET 2012 Survey. Helsinki: THL.

21. Hoppu U, Lehtisalo J, Tapanainen H, et al. (2010) Dietary habits and nutrient intake of Finnish adolescents. Public Health Nutr 13, 965-972.

22. Kyttälä P, Erkkola M, Kronberg-Kippilä C, et al. (2010) Food consumption and nutrient intake in Finnish 1-6-year-old children. Public Health Nutr 13, 947-956.

23. Agence française de sécurité sanitaire des aliments (2009) Étude Individuelle Nationale des Consommations Alimentaires 2 (INCA 2) 2006-2007 (version 2) (Report of the 2006/2007 Individual and National Study on Food Consumption 2 (INCA 2) (version 2)). Maisons-Alfort: AFSSA.

24. Banasiak U, Heseker H, Sieke C, et al. (2005) Estimation of the dietary intake of pesticide residues based on new consumption data for children. Bundesgesundheitsblatt, Gesundheitsforschung Gesundheitsschutz 48, 84-98.

25. Mensink GB, Bauch A, Vohmann C, et al. (2007) EsKiMo - the nutrition module in the German Health Interview and Examination Survey for Children and Adolescents (KiGGS). Bundesgesundheitsblatt, Gesundheitsforschung Gesundheitsschutz 50, 902-908.

26. Irish Universities Nutrition Alliance (2011) National Adult Nutrition Survey (NANS). Dublin: IUNA.

27. Sette S, Le Donne C, Piccinelli R, et al. (2011) The third Italian National Food Consumption Survey, INRAN-SCAI 2005-06 - part 1: nutrient intakes in Italy. Nutr Metab Cardiovasc Dis 21, 922-932.

28. Van Rossum C, Fransen H, Verkaik-Kloosterman J, et al. (2011) Dutch National Food Consumption Survey 2007-2010: Diet of Children and Adults Aged 7 to 69 Years. Bilthoven: National Institute for Public Health and Environment (RIVM).

29. Amcoff E, Edberg A, Enghardt Barbieri H, et al. (2012) Riksmaten - vuxna 2010-11. Livsmedels- och näringsintag bland vuxna $i$ Sverige. Resultat från matvaneundersökning utförd 2010-11 (Riksmaten - Adults 2010-11. Food Consumption and Nutrient Intake Among Adults in Sweden. 
Results from the Dietary Survey Carried out in 2010-11). Uppsala: Livsmedelsverket.

30. Department of Health and Food Standards Agency (2012) National Diet and Nutrition Survey (NDNS). Headline Results From Years 1, 2 and 3 (Combined) of the Rolling Programme (2008/2009-2010/2011). Dublin: Department of Health and Food Standard Agency.

31. Beer-Borst S \& Amado R (1995) Validation of a self-administered 24-hour recall questionnaire used in a large-scale dietary survey. Z Ernahrungswiss 34, 183-189.

32. Rutishauser IH (2005) Dietary intake measurements. Public Health Nutr 8, 1100-1107.

33. Ortega RM, Perez-Rodrigo C \& Lopez-Sobaler AM (2015) Dietary assessment methods: dietary records. Nutr Hosp 31, 38-45.

34. European Food Safety Authority (2009) General principles for the collection of national food consumption data in the view of a pan-European dietary survey. EFSA J 7, 1435.

35. Koc H, Mar MH, Ranasinghe A, et al. (2002) Quantitation of choline and its metabolites in tissues and foods by liquid chromatography/electrospray ionization-isotope dilution mass spectrometry. Anal Chem 74, 4734-4740.
36. Ireland JD \& Moller A (2010) LanguaL food description: a learning process. Eur J Clin Nutr 64, S44-S48.

37. European Food Safety Authority (2014) Guidance on the EU Menu methodology. EFSA J 12, 3944.

38. Cho E, Zeisel SH, Jacques P, et al. (2006) Dietary choline and betaine assessed by food-frequency questionnaire in relation to plasma total homocysteine concentration in the Framingham Offspring Study. Am J Clin Nutr 83, 905-911.

39. Chiuve SE, Giovannucci EL, Hankinson SE, et al. (2007) The association between betaine and choline intakes and the plasma concentrations of homocysteine in women. Am J Clin Nutr 86, 1073-1081.

40. Food and Drug Administration (2013) Everything added to food in the United States (EAFUS). http://www.accessdata.fda. gov/scripts/fcn/fcnNavigation.cfm?filter=choline\&sortColumn= \&rpt=eafusListing (accessed July 2015).

41. European Parliament (2006) Regulation (EC) No 1925/2006 of the European Parliament and of the Council of 20 December 2006 on the addition of vitamins and minerals and of certain other substances to foods. http://eur-lex.europa.eu/legal-content/EN/TXT/?uri=CELEX:32006R1925 (accessed July 2015). 